\title{
Visualization of optimized solution space using a simulation system for the development of local forest management planning
}

\author{
E. T. Nakajima, H. Kanomata, M. Matsumoto
}

Nakajima T., Kanomata H., Matsumoto M., 2016. Visualization of optimized solution space using a simulation system for the development of local forest management planning. Ann. For. Res. 59(1): 117-128.

Abstract. A simulation system, based on pre-existing models, was used to investigate and visualize the solution space for optimizing forest management planning. The simulation system used existing forestry profits estimation models to test the outcomes of different crop rotations by previous studies. The simulation enabled us to predict forestry profits and labor requirements under different forestry management plans, and to examine the consequences for harvesting strategies. A part of the Kyushu region was selected as the study site, because the basic sub-models for predicting timber production, labor requirements and forestry profits were developed in the area. This study has investigated and visualized the solution space optimized for forest economics using various combinations of short and long rotation silvicultural practices implemented at a local scale. Based on the simulations, optimization of the plans was formulated under the forestry scale of compartment and total level. Visualizing the 3-dimensional optimized solution space by using a simulation system is useful for decision-makers involved with local forest management planning. The differences of forestry profits, labor requirements and timber volume depending on the intensity of silvicultural practices were analyzed. The simulation system is also useful for sustainable forest management under the Japanese forestry planning system.

Keywords economics, labor quantity, optimization, solution space, timber production

Authors. Nakajima Tohru (nakajima@fr.a.u-tokyo.ac.jp) - University of Tokyo, Laboratory of Forest Management, Graduate School of Agricultural and Life Sciences, the University of Tokyo, 1-1-1 Yayoi, Bunkyo-ku, Tokyo 113-8657, Japan; Kanomata Hidesato, Matsumoto Mitsuo - Forestry and Forest Product Research Institute, 1 Matsunosato, Tsukuba 305-8687, Japan.

Manuscript received July 21, 2015; revised November 04, 2015; accepted November 20, 2015; online first March 17, 2016. 


\section{Introduction}

Although one of the traditional uses of forests has always been timber production (Clutter et al. 1983), today such production should be based on sustainable management planning. Forestry human prescriptions such as harvesting timber for economic activity make sense for their environmental functions, such as acting as carbon sinks, contributing to biodiversity, and protecting water resources (Pukkala 2002). For forest management plans that consider the full range of forest values and longterm sustainability, appropriate target levels have to be decided. At a local scale, the focus of sustainability could be societal continuity, for example by creating sustainable employment for a regional community, as well as environmental stability at a global scale. The targets must be local scale, regarded here as landscape scale, as defined by Helms (1998), such as the creation of sustainable employment for a regional community to promote social continuity, and should not conflict with global scale objectives, such as mitigating global climate change. To optimize local forest planning, it is therefore necessary to be able to predict the suitability of proposed plans, not only as applied to the natural resources such as the timber, but also to the local labor market.

In addressing issues of sustainability management, including sustaining a workforce, the Forest Ecosystem Management Assessment Team (1993) have recommended using adaptive management frameworks, such as the PDCA throughout the world (Millennium Ecosystem Assessment Board 2005). There are differences among definitions (Stankey et al. 2005, Beier et al. 2009), but adaptive management (Sinclair et al. 2015, Reyer et al. 2015) based on PDCA cycles is recommended by certification bodies such as the Forest Stewardship Council (FSC) (Gulbrandsen 2005).

PDCA cycle consists of the following four phases: Plan (P), Do (D), Check (C) and Act (A). The Plan phase involves considering pos- sible ways to meet specified objectives or targets. The option selected in the Plan phase is implemented in the Do phase. The degrees to which objectives and targets have been met are evaluated in the Check phase (and new baselines may be established if the Plan and Do phases have delivered improvements). Strategies for the future are then considered in the Act phase, and the outcome of the review may or may not trigger a new PDCA cycle (Forest Ecosystem Management Assessment Team 1993).

As mentioned above, within the PDCA management structure, it would be useful to be able to apply forest planning prediction models that facilitate realistic and rational decision-making, especially in the Plan and Act phases. Although previous studies have analyzed labor intensity based on past forest management history (Moseley et al. 2014), there have been few attempts to develop a simulation system capable of predicting future forestry profits, employment and timber supplies that could support long-term sustainable planning in Japan. The need for such a system has been raised by plans to approximately triple national timber production, to levels regarded as reasonable based on average national volume growth of approximately 80 million $\mathrm{m} 3$, during the coming 30 years (Forestry Agency 2014). Thus, it is clearly important to establish management systems that enable timber production to be increased while sustainably managing forest resources. Therefore, the aim of the study presented here was to construct a predictive model for Japanese forestry employment, timber production and profit by simulating future outcomes based on final cutting silvicultural practices in a forestry area in Miyazaki, a prefecture where timber productivities are amongst the highest nationally. 


\section{Materials and methods}

\section{Study site}

Morotsuka village, Miyazaki Prefecture, was selected as the study site. Miyazaki Prefecture is located in the Kyushu region of Japan (Fig. 1) and produces the largest quantity of timber products in the country. Morotsuka village is located in a warm temperate zone, with an average annual temperature of approximately $14{ }^{\circ} \mathrm{C}$ and average annual rainfall of about $2445 \mathrm{~mm}$. Forests cover a total area of 17785 ha in the prefecture, with 12541 ha in the forest plantation of Morotsuka village, of which 11629 ha $(92.7 \%)$ hold stands of Japanese cedar (Cryptomeria japonica), and 912 ha $(7.3 \%)$ hinoki (Chamaecyparis obtusa). The target areas were all forest plantations, shown in Fig. 2, mainly consisting of C.japonica stands between 30 and 50 years old, which were widely planted when the timber price was relatively high throughout Japan, and thus are common now (Forestry Agency 2007). Morotsuka village forest already has FSC certification, which in 2004 stipulated requirements for maintaining sociological and economic sustainability. It was important, therefore, to consider a forest management scheme that maintains the sustainability of timber production and the labor force employed in the area. At the study site, forest thinning is carried out by workers from a forestry cooperative supported by subsidies from the government. The total average annual growth in this area was approximately $17,000 \mathrm{~m}^{3}$. The local yield table construction system (LYCS) could be applied to the tree species, including Japanese cedar (C. japonica), that are most widely planted throughout Japan (Nakajima et al. 2010). The harvested timber volume, forestry profits and labor requirements could be predicted using a simulation that included the LYCS model along with a wood conversion algorithm and a harvesting cost model (Nakajima et al. 2011a).

\section{Data analysis}

The existing models were developed to estimate forestry profits, and labor requirements for the harvested area under short and long silvicultural rotations (Nakajima et al. 2010; Nakajima et al. 2009b; Nakajima et al. 2009a, b, Oka 2006). Two rotation groups were con-

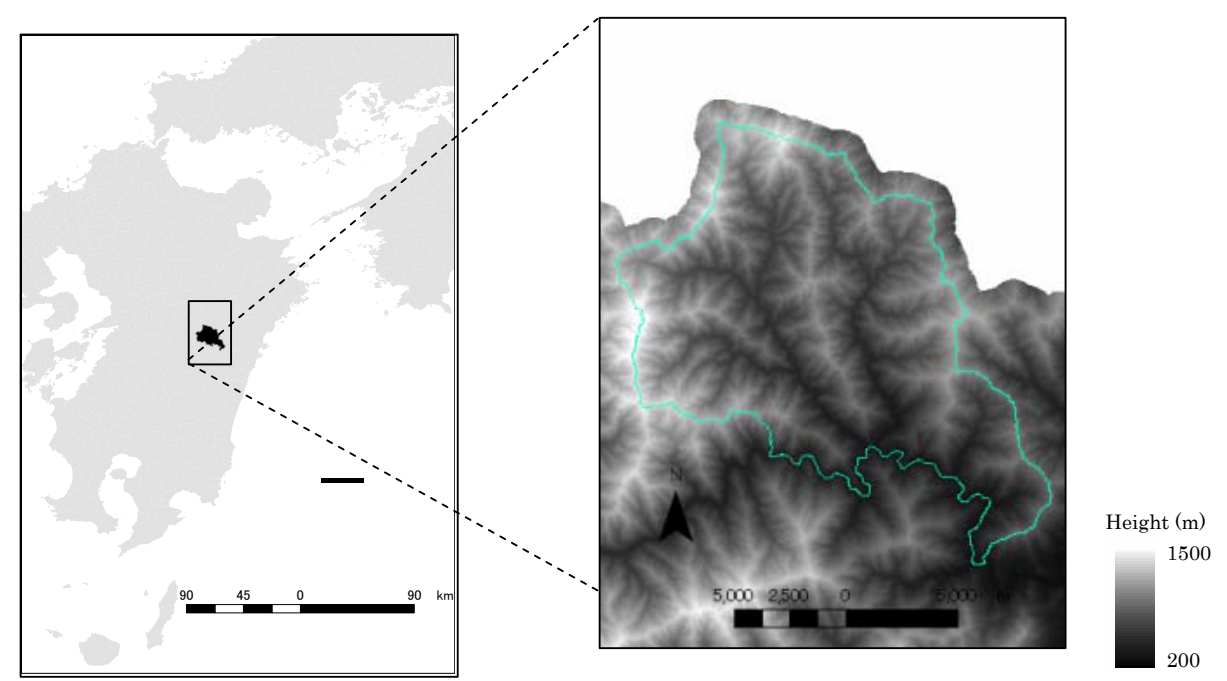

Figure 1 The study site located in Morotsuka village. The blue line shows the boundary line of Morotsuka village 


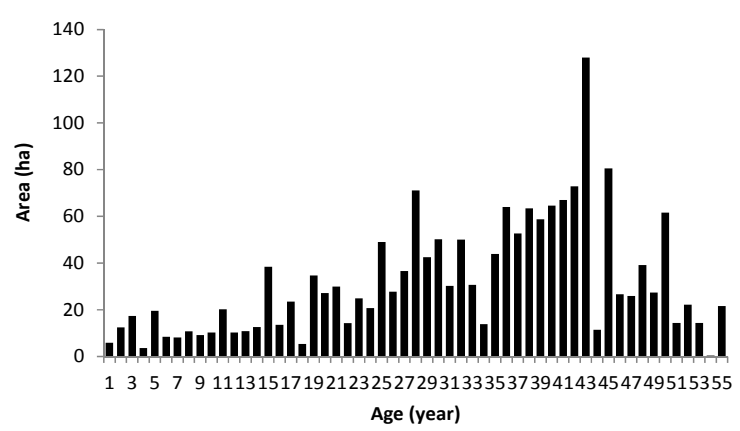

Figure 2 The age distribution of forested areas in the target study site

sidered: group 1 included short rotation stands less than 75 years old as the optimum final cutting age, while group 2 included short rotation stands more than 76 years old as the optimum final cutting age. As described below, different silvicultural practices (Nakajima et al. 2011a), including no management for each stand, were derived from previous studies and were used for optimizing the modeling.

The harvesting strategies were chosen to maximize the net present value (Davis \& Johanson 1987, Nakajima et al. 2011a).

We varied the final cutting age for each stand by 5 -year increments from 50 years to 75 years (group 1) and from 76 years to 100 years (group 2), in line with existing standard silviculture practices (Nakajima et al. 2011a). The total forestry profits, labor requirements, and timber production depending on the combination of short and long rotation stands implemented as the silvicultural practice were estimated by using the models mentioned above.

Because the total net present value is approximately equal to the soil expectation value (SEV) for long prediction periods such as 200 years (Davis et al. 2001), the simulation periods were set at 200 years. By combining these tools and a harvesting allocation tool (Nakajima et al. 2011b), we could estimate the harvest area. Harvest allocation is the main problem in forest management and one of the major factors affecting revenues from forests and their sustainability (Bettinger et al. 2009).
Several strategies can be applied, and the approach applied here could be categorized as sequential, according to Davis et al. (2001). First, unique ID numbers linked to the geographic information system (GIS) managed by the prefectural government were assigned to all of the sub-compartment areas (Nakajima et al. 2011a), which were alloca- ted to rotation groups 1 or 2 (described above). Then, harvest schedules over the planning interval were established for each sub-compartment by considering its conditions, such as area, stand age, topography and associated growth rate (Nakajima et al. 2011a). If the harvesting schedule for any sub-compartment was adjusted after the following optimization of silvicultural practices, the associated harvesting allocation was automatically updated through the linkage between sub-compartments and the GIS. Based on the simulations, the plans were optimized as follows. The harvesting plans were basically implemented at the level of compartments, which were usually bordered by topographic boundaries such as mountains or valleys. Information about these boundaries is included in the administrative GIS. Thus, compartment level optimizations were initially generated:

$\max P=\sum_{i=1}^{I} \sum_{j=1}^{J} p_{i, j} x_{i, j} n$

where $p_{i, j}$ - forestry profits at the stand level associated with option $j$ for stand $i$ (yen), $I$ - total number of stands in the compartment, $J$ - total number of selectable silvicultural practices for the stand, $P$ - forestry profit at the compartment level (yen), $x_{i, j}$ - binary variable that was set as equal to 1 if option $j$ was chosen for stand $i$ and to 0 otherwise, $n$ - binary variable that was set as equal to 1 if option $j$ could be implemented and to 0 otherwise.

Second, based on the compartment optimizations, the total optimization was then determined: 
$\max Z=\sum_{k=1}^{K} \sum_{l=1}^{L} P_{k, l} y_{k, l}$

where: $P_{k, l}$ - forestry profits at the compartment level associated with option $l$ for compartment $k$ (yen), $K$ - total number of compartments in the total area, $L$ - total number of selectable silvicultural practices for the compartment, $Z$ - forestry profits of the total area (yen), $y_{k, l}$ - binary variable that was set as equal to 1 if option $l$ was chosen for compartment $k$ and to 0 otherwise. Subject to:

$L_{t}-1500<\sum_{k=1}^{K} \sum_{l=1}^{L} L_{k, l} y_{k, l}<L_{t}+1500$

where: $L_{k, l}$ - labor employment (person-day), $L_{t}$ - average labor employment level per year throughout the prediction period. And:

$T_{t}-3000<\sum_{k=1}^{K} \sum_{l=1}^{L} T_{k, l} y_{k, l}<T_{t}+3000$

where: $T_{k, l}$ - timber volume $\left(\mathrm{m}^{3}\right), T_{t}$ - average volume level per year throughout the prediction period.

The constant values in these formulas, such as 1500 and 3000, were assumed by consulting with the forestry staff in the study area. The Japanese government actively promotes increased self-sufficiency through domestic timber production. Thus the restrictions controlling suitability were set after 25 years, which was set by considering the vision of national government (Science Council 2008).

Timber production and labor requirement constraints were applied because they are important for maintaining stable timber supplies for mills owned by the Japanese forestry associations and the efficient use of manpower they manage, respectively. The stability of forestry profits is less important in the target area because the forests are owned by (and total forestry profits are distributed among) a number of small non-industrial private forest owners. Thus, their shares of profits are relatively small, and they gain most of their income from other sources. Based on the optimization, the ratio of long and short silvicultural rotations was calculated for each simulation:

$R_{l}=\frac{A I_{l}}{A_{l}}$

$R_{s}=\frac{A I_{s}}{A_{s}}$

where: $R_{l}$ - ratio of long rotation silvicultural practice, $R_{s}$ - ratio of short rotation silvicultural practice, $A I_{I}$ - area implementing long rotation silvicultural practice, $A I_{\mathrm{s}}$ - area implementing short rotation silvicultural practice, $A_{1}$ - total area of stands selected for a long rotation silvicultural practice, $A_{\mathrm{s}}$ - total area of stands selected for a short rotation silvicultural practice. The simulation started from 2015.

Using the output data derived from simulations as input, the combinations of silvicultural practices for all the sub-compartments were optimized using a genetic algorithm (Holland 1975), which has been widely applied in forest management optimizations (Bettinger et al. 2002, Pukkala 2002). Fifty random solutions were used as starting points, following Yousefpour and Hanewinkel (2014), with mean values $(0.5)$ for cross-over and mutation probabilities, following Falcão \& Borges (2001), throughout all the prediction periods.

We stopped the optimization when the slope of linear regression in the last 100 solutions was less than 0.01 and selected the best solution from these solutions.

A contribution index, that treats forestry profits as an objective function, based solely on main effects ( $\mathrm{Gu} 2002$ ), was also calculated:

$C_{i}=\frac{V_{i}}{V[Z]}$

where: $C_{i}$ - contribution index of the ratio of short rotation $(i=1)$ to long rotation $(i=2)$, $V[Z]$ - variance of forestry profits over the total area, $V_{\mathrm{i}}$ - variance of $Z$ depending on the ratio of short rotation $(i=1)$ to long rotation 
$(i=2)$.

Because there are only two variances, both depending on the ratio of short to long rotation, we assumed that interactions could be ignored, thus simplifying the calculations. The relationship between $V[Z]$ and $V_{i}$ was calculated using the following formula and the smoothing spline ANOVA method (Gu 2002).

$$
V[Z]=\sum_{i=1}^{2} V_{i}
$$

\section{Results}

The 3-dimensional solution spaces estimated by the optimizations show various self-explanatory features. A noteworthy feature is the greater density of contour lines in the boxed area A (in which the short rotation ratio is relatively high) than in the boxed area B (in which the long rotation ratio is relatively high) in Fig. 3b. This indicates that the solution stability is greater when the long rotation ratio is relatively high. Figure 3 also shows that plans

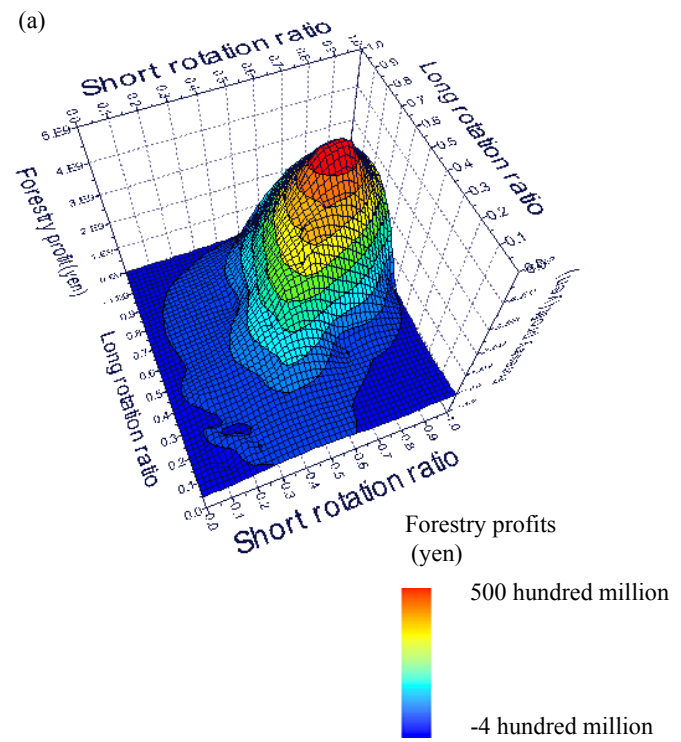

implementing a short and long rotation ratio less than 0.4 (part $C$ enclosed by a blue line in Fig. 3b) do not give the highest forestry profits. The plans implementing the maximum short and long rotation ratio of more than 0.8 (part $\mathrm{D}$ enclosed by a blue line in Fig. 3b) also do not give the highest forestry profits, because the costs would also be increased by the application of silvicultural practices to almost all the stands.

The contribution index of short and rotation silvicultural practices were 0.6 and 0.4 , respectively. The contribution index of short rotation silvicultural practice was larger than that of long rotation silvicultural practice with ratios of approximately $6: 4$, which indicates a relatively strong effect on the total forestry profits. These results were justified by the fact that the collinearities ( $\mathrm{Gu} 2002$ ) of two variables (the ratio of short rotation and long rotation) were approximately 1.07 , which is almost 1.0 .

\section{Timber production}

Figure 4 shows that the timber harvest was

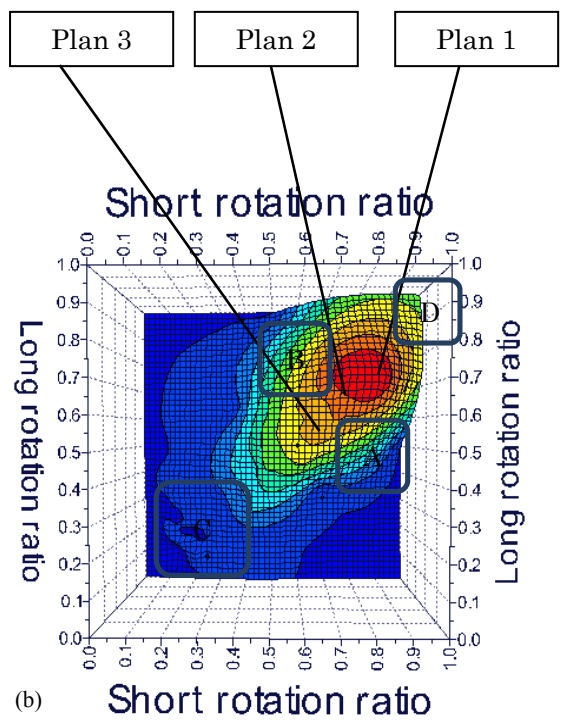

Figure 3 Visualization of the 3-dimensional solution spaces showing (a) the forestry profit and (b) the allocation of sample plans 1-3 
larger under plan 1 than under plans 2 and 3. From the initial value, the timber production increased up to approximately $350 \%$ of its minimum value. After the 25 th year, the volume of harvested timber fluctuated between $14000 \mathrm{~m}^{3}$ and $8000 \mathrm{~m}^{3}$. The average timber volume per year with plan 1 was approximately $10000 \mathrm{~m}^{3}$. As mentioned in the Methods section and shown in the Results section, the even flow constraint was established after 25 years.

After the 25th year, the timber harvest under plan 2 was smaller than that of plan 1, with the minimum and maximum values for the tim-
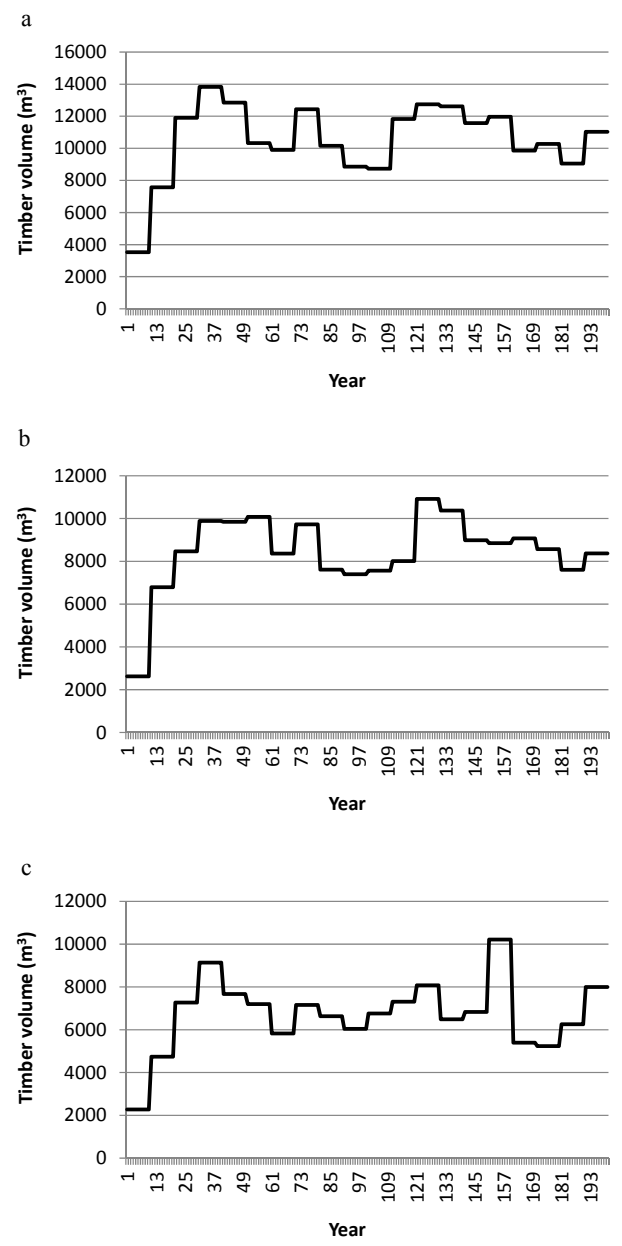

Figure 4 The harvested timber volume under (a) plan 1, (b) plan 2 and (b) plan 3 ber being 7396 (85\% of that for plan 1) and 10919 (79\% of that for plan 1), respectively. The harvested timber volume increased up to about $440 \%$ of its minimum value (Fig. 4b). After the 25th year, the volume of harvested timber fluctuated between $11000 \mathrm{~m}^{3}$ and 7000 $\mathrm{m}^{3}$. The average timber volume per year with plan 2 was approximately $8400 \mathrm{~m}^{3}$.

After the 25th year, the timber harvest under plan 3 was smaller than that of plan 1, with the minimum and maximum values for the timber being 5236 (60\% of that for plan 1) and 10215 (74\% of that for plan 1), respectively. The harvested timber volume increased up to $400 \%$ of its minimum value (Fig. 4c). After the 25th year, the volume of harvested timber fluctuated between $10000 \mathrm{~m}^{3}$ and $6000 \mathrm{~m}^{3}$. The average timber volume per year with plan 3 was approximately $6700 \mathrm{~m}^{3}$.

As mentioned in the Introduction, the Japanese government is actively promoting increases in timber production. So, these trends could meet Japanese national forestry policy objectives, balancing increases in timber production and sustainable forest management, after 25 years. Although the increase is higher than the national increase specified by the Japanese forestry agency, these results would be realistic because the target area is covered by planted forest that has among the highest growth rates in Japan (Nakajima et al. 2010). Furthermore, under all plans 1 to 3 , the average timber volumes were less than the total average annual volume increment $\left(17,000 \mathrm{~m}^{3}\right)$ in this area.

\section{Labor requirements}

Figure 5 shows the differences in labor requirements for the three plans. The labor requirements were larger for plan 1 than for plans 2 and 3. From the initial value, the labor requirements increased up to $500 \%$ of the minimum value. After the 25 th year, the volume of harvested timber fluctuated between 3000 person-days and 5500 person-days. The average 

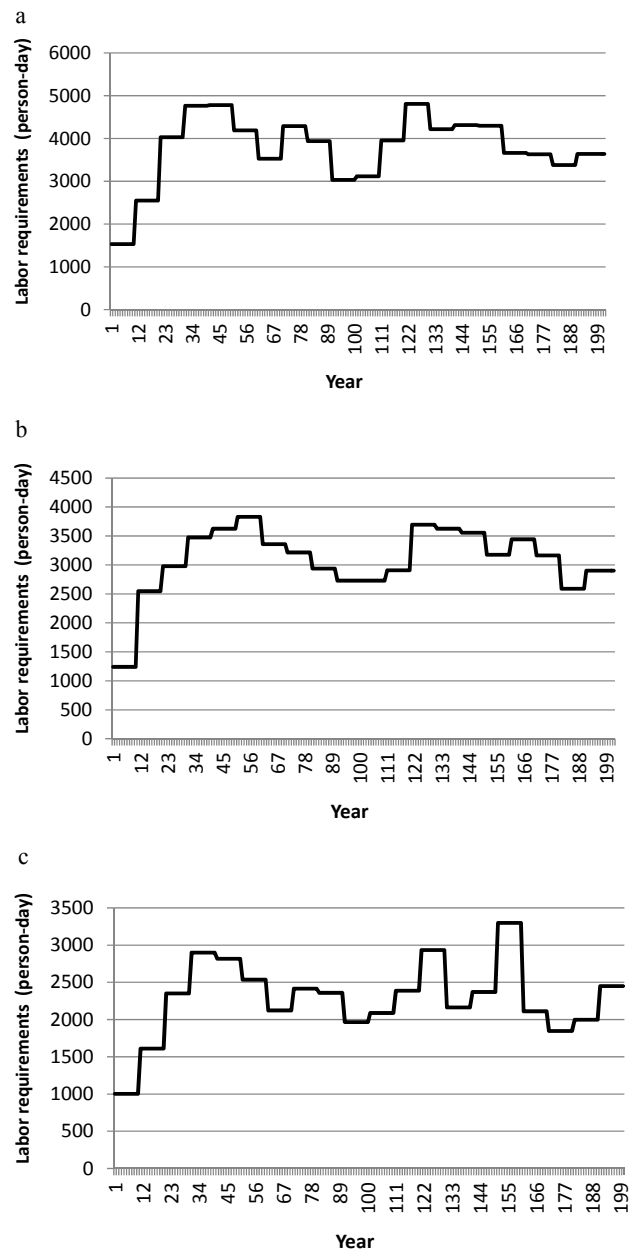

Figure 5 The labor requirements under (a) plan 1, (b) plan 2 and (b) plan 3

labor requirements per year for plan 1 were approximately 3800 person-days.

After the 25th year, the labor requirements under plan 2 were smaller than those for plan 1 , with minimum and maximum values of $2589(85 \%$ of that for plan 1$)$ and $3829(80 \%$ of that for plan 1), respectively. The labor requirements increased up to $400 \%$ of the minimum value (Fig. 5b). After the 25 th year, the labor requirements fluctuated between about 2500 person-days and 4000 person-days. The average labor requirements per year for plan 2 were approximately 3000 person-days.

After the 25th year, the labor requirements 124 under plan 3 were smaller than those for plan 1 , with minimum and maximum values of 1847 (61\% of that for plan 1) and $3296(69 \%$ of that for plan 1), respectively.

The labor requirements increased up to about $430 \%$ of the minimum value (Fig. $5 \mathrm{c}$ ). After the 25th year, the labor requirements fluctuated between 1750 person-days and 3500 person-days. The average labor requirements per year for plan 3 were approximately 2300 person-days.

\section{Forestry profits}

Figure 6 shows the differences in forestry profits for the three plans. Under plan 1, the forestry profits were larger than plans 2 and 3. From the initial value, the forestry profits increased up to 35 million yen. After the 25th year, the forestry profits fluctuated between 10 million yen and 35 million yen. The average forestry profits per year for plan 1 were approximately 20 million yen.

After the 25th year, the forestry profits under plan 2 were smaller than those for plan 1, with minimum and maximum values of $8,366,710$ (69\% of that for plan 1) and 27,899,521 (79\% of that for plan 1), respectively. The forestry profits increased up to about 30 million yen (Fig. 6b). After the 25th year, the forestry profits fluctuated between about 8 million yen and 28 million yen. The average forestry profits per year for plan 2 were approximately 15 million yen. After the 25th year, the forestry profits under plan 3 were smaller than those for plan 1, with minimum and maximum values of $1,040,122(9 \%$ of that for plan 1) and $19,645,711(56 \%$ of that for plan 1$)$, respectively. The forestry profits increased up to 20 million yen (Fig. 6c). After the 25th year, the forestry profits fluctuated between 1 million yen and 20 million yen. The average forestry profits per year for plan 3 were approximately 10 million yen. 


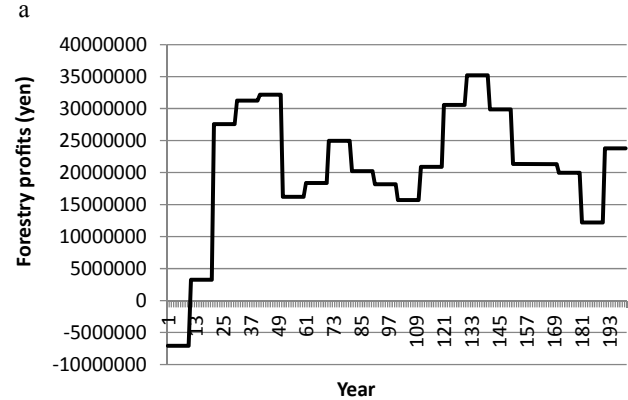

b

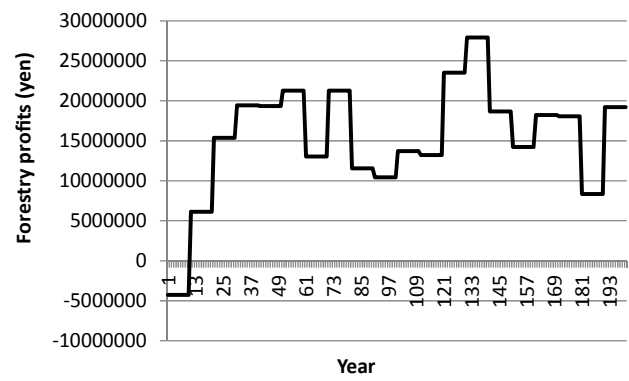

c

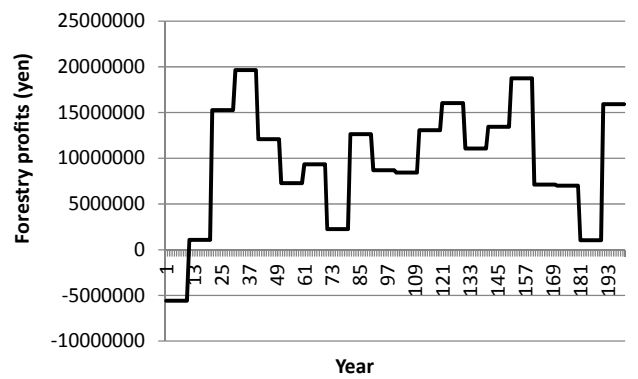

Figure 6 The forestry profits under (a) plan 1, (b) plan 2 and (b) plan 3

\section{Discussion}

A visualization of the solution space arising from this study is shown in Fig. 3. The solution space could be altered by varying the social and economic parameters. By comparing various optimized solution spaces, a greater understanding of the influence of the different parameters could be achieved.

The first useful information to be derived from the solution space was a visualization of solution stability. In the solution space shown in Fig. 3, the higher the density of the contour lines, the lower the stability of the forestry profits. Conversely, the lower the density of the contour lines in Fig. 3, the higher the stability of the forestry profits. This means that the density of the contour lines indicates the stability of the objective function. Part A in Figure 3b, in which the density of the contour lines is relatively high, shows a lower solution stability than Part B in Fig. 3b, in which the density of the contour lines is relatively low. This means that Part A, in which the short rotation ratio is relatively high, has a lower solution stability than Part B, in which the long rotation ratio is relatively high. These results reflect the fact that the short rotation ratio has a stronger effect on the objective function, as shown by the contribution index. The short rotation stands produce higher forestry profits per unit area than long rotation stands. Therefore, forestry profits are strongly affected by the silvicultural rotation ratio implemented, as shown in Part A compared with Part B. As indicated above, the visualization of solution space is useful for considering profit stability, which could not be clarified by estimating only one optimum solution.

The second advantage derived from the solution space is clarification not only of the most desirable solution but also various undesirable solutions, i.e. plans implementing a short and long rotation ratio less than 0.4 (part $\mathrm{C}$ enclosed by a blue line in Fig. 3b), the maximum short and long rotation ratio of more than 0.8 (part D enclosed by a blue line in Fig. $3 b$ ), and so on. Identifying such trends from the solution space means non-optimum forest management planning can be avoided. Visualization of the solution space provides the means to review forest management policy by highlighting various undesirable planning options.

In this study, the timber volume estimate was predicted using the Japanese national government policy of promoting the increase of domestic lumber production for the future. 
Of course, the desired supply of timber volume depends on the timber demands of a local region. Therefore, the level of timber production set should be based on the actual local forestry product demands of the target area. This study also predicted the labor requirements for various silvicultural practices. Predicting the labor requirements is useful not only for checking the feasibility of certain forest management plans, but also for considering the growth of employment created by local forest management. In order for local municipal governments to maintain social and economic sustainability and prevent depopulation of mountainous areas of Japan, job sustainability is an important consideration for policy-makers. If the local labor requirements cannot be met, it is difficult to encourage people to move to and remain in rural settlements. The development of the simulation system used in this study enabled us to quantify sustainable job creation by selecting different forest management planning options.

The simulators for predicting future stand growth included in this model have been validated by comparing their results for variables such as tree growth with data obtained from observations in permanent plots (Nakajima et al. 2011c). Effects of possible options on economic variables considered in this study, such as timber production levels and forestry profits (Nakajima et al. 2011a), were estimated using stand and forest level data. So, these results should remain accurate if socio-economic conditions do not dramatically change in the future. Sharp changes in socio-economic factors such as timber prices and harvesting systems could affect the results. However, the input data for the system including the models proposed in this study could be flexibly changed by users such as forestry practitioners, managers and policy makers. So, in "Act" phases (Fig. 7) it would be important to amend predictions and planning schedules in accordance with current socio-economic conditions and new data obtained, for instance, by remote sensing technologies (Vauhkonen et al. 2014). Based on the validation, one of the applications of this simulation system is as a decision support tool (Buongiorno, Gilless 2003) for developing forest management plans for practical operations. Decision support systems have been addressed by many authors for some of the relevant parameters, including carbon stocks (e.g. Garcia-Gonzalo et al. 2014), land use (e.g. West \& Turner 2014), and harvesting (Wu et al. 2012).

Data on the timber volume, silvicultural practices for each stand and so on, are required for local forest management plans. The output from the simulation system includes these data. Thus the simulations can help policy-makers and forestry practitioners propose policy changes that not only consider timber production, but also fulfill labor requirements.

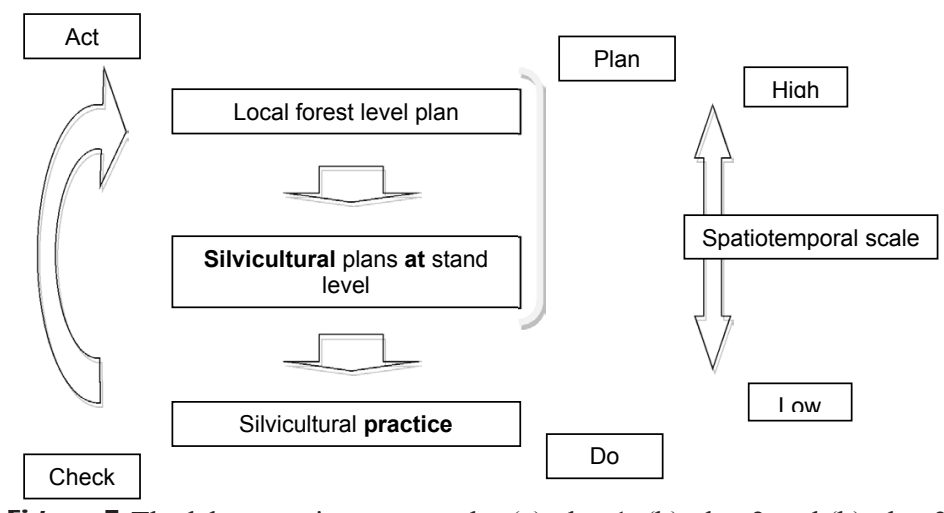

Figure 7 The labor requirements under (a) plan 1, (b) plan 2 and (b) plan 3 
If results of this study were combined with those of previous evaluations of ecosystem services (Garcia et al. 2015, Wang et al. 2010), a decision support system for estimating the balance between economic and environmental functions could be constructed.

If a PDCA is used for forest management, it needs to take local labor requirements into account (Fig. 5). Figure 7 shows a model of Plan-Do-Check-Act considering the practical forest management.

Based on the Plan phase, including determining the labor requirements, timber production, forestry profits etc. (Do), the outcomes of the silvicultural practice employed can be monitored (Check). Such a check phase provides the information needed to revise the next planning phase (Act). Constraints such as presented in the equations above would be useful for improvement of establishing practical plans. The plans selected to maintain natural resources and sociological sustainability in local forest area can be maintained to account for the labor requirements in the forestry sector.

In this study, a simulation system that enabled us to increase the output of information optimized for the profitable and sociological output depending on the various plans such as labor requirements related to PDCA cycles (Fig. 8) has been developed. Thus, policy-makers should take into consideration various plans in order to meet feasible constraints and stability. The next challenge is to test the estimation and practical utility of the simulation by comparing it with real outcomes.

\section{Conclusions}

This study used existing models to estimate economic and sociological effects on labor requirement of three plans describing alternative short and long silvicultural rotations applied to Japanese forestry. The simulation output showed that both the harvested area and the volume of harvested timber were larger under plan 1 than under plan 2 and 3. Forestry prof- its were also larger under plan 1 than plans 2 and 3. However, the labor requirements were smaller under plans 2 and 3 than under plan 1 . The results suggested that optimum management planning could be improved by considering the forestry outcomes and labor requirements depending on the various intensities of short and long rotation silvicultural practices.

\section{Acknowledgments}

The authors wish to thank the staff members of the Forestry Association of Mimi River for their cooperation to questionnaire survey and assist with data collection. This study was supported in part by Research Fellowships from the Japanese Science Promotion Society. The authors gratefully acknowledge all reviewers and Editorial Board/Office for their helpful comments, which greatly improved the previous versions of this manuscript.

\section{References}

Beier C.M., Lovecraft A.L., Chapin F.S., 2009. Growth and collapse of a resource system: an adaptive cycle of change in public lands governance and forest management in Alaska. Ecology and Society, 14 (2): 5.

Bettinger P., Boston K., Siry J. P., Grebner, D. L., 2009. Forest Management and Planning. Academic Press, Burlington.

Bettinger, P., D. Greatz, K. Boston, J. Sessions, W. Chung., 2002. Eight heuristic planning techniques applied to three increasingly difficult wildlife planning problems. Silva Fennica, 36:561-584. DOI: 10.14214/sf.545

Buongiorno J., Gilless K.J., 2003. Decision Methods for Forest Resource Management. California, Academic Press, $439 \mathrm{p}$.

Clutter, J.L., Fortson, J.C., Pienaar, L.V., Brister, G.H. and Bailey, R.L. (1983) Timber Management: A Quantitative Approach, John Wiley \& Sons, Chichester.

Davis L.S., Johanson K.N., 1987. Forest management. McGraw-Hill, New York.

Davis L.S., Johanson K.N., Bettinger P., Howard T.E., 2001. Forest management to sustain ecological, economic and social values. McGraw-Hill, New York

Falcão A.O., Borges J.G. 2001. Designing an evolution program for solving integer forest management scheduling models: An application in Portugal. Forest. Science 47:158-168.

Forestry Agency 2007. Annual report on trends of forest 
and forestry-fiscal year 2006. Tokyo, Japan Forestry Association, $17 \mathrm{p}$.

Forestry Agency 2014. Forestry statistics. Tokyo, Japan Forestry Association, 260 p. (in Japanese)

Forest Ecosystem Management Assessment Team, 1993. Forest ecosystem management: an ecological, economic, and social assessment. US Department of Agriculture, Forest Service; US Department of Commerce, National Oceanic and Atmospheric Administration, US Department of Interior, Bureau of Land Management, U.S. Fish and Wildlife Service, and National Park Service; and Environmental Protection Agency, Washington DC, $139 \mathrm{p}$.

Garcia-Gonzalo, J., Borges, J. G., Palma, J. H. N., Zubizarreta-Gerendiain, A. 2014. A decision support system for management planning of Eucalyptus plantations facing climate change. Annals of Forest Science 71 (2): 187-199. DOI: 10.1007/s13595-013-0337-1

Garcia-Gonzalo, J., Bushenkov, V., McDill, ME., Borges, J. G. 2015. A decision support system for assessing trade-offs between ecosystem management goals: An application in Portugal. Forests 6 (1): 65-87. DOI: 10.3390/f6010065

Gu C., 2002. Smoothing spline ANOVA models. Springer-Verlag Inc. DOI: 10.1007/978-1-4757-3683-0

Gulbrandsen L. H., 2005. Mark of sustainability? Challenges for fishery and forestry ecolabeling. Environment 47 (5), 8-23. DOI: 10.3200/ENVT.47.5.8-23

Helms J. A. 1998. The Dictionary of Forestry. Bethesda, MD: Society of American Foresters, 125 p.

Holland, J.H., 1975. Adaptation in natural and artificial systems. University of Michigan Press, Ann Harbor, MI.

Millennium Ecosystem Assessment Board. 2005. Millennium ecosystem assessment: ecosystems and human well-being: synthesis. Island Press: Washington, $137 \mathrm{p}$.

Moseley C., Sandoval G., Davis E. J., 2014. Comparing conditions of labor-intensive forestry and fire suppression workers. Society \& Natural Resources 27 (5) :540556. DOI: $10.1080 / 08941920.2014 .888792$

Nakajima T., Kanomata H., Matsumoto M., Tatsuhara S., Shiraishi N., 2009a. The application of "Wood Max" for total optimization of forestry profits based on joint implementation silvicultural practices. Kyushu Journal of Forest Research 62: 176-180.

Nakajima T., Kanomata H., Matsumoto M., Tatsuhara S., Shiraishi N., 2011a. Cost-effectiveness analysis of subsidy schemes for industrial timber development and carbon sequestration in Japanese forest plantations. Journal of Forestry Research. 22 (1):1-12. DOI: 10.1007/s11676-011-0117-4

Nakajima T., Kanomata H., Tatsuhara S., Shiraishi N. 2011b. Simulation of the spatial distribution of thinning area under different silvicultural subsidy systems in Japanese plantation forests. Folia Forestalia Polonica 53 (1): 3-16.

Nakajima T., Matsumoto M., Shiraishi N., 2011c. Modeling diameter growth and self-thinning in planted sugi (Cryptomeria japonica) stands. The Open Forest Science Journal. 4: 49-56. DOI: $10.2174 / 1874398601104010049$
Nakajima T., Matsumoto M., Tatsuhara S., 2009b. Development and application of an algorithm to estimate and maximize stumpage price based on timber market and stand conditions. Journal of Forest Planning 15:21-27.

Nakajima T., Matsumoto M., Sasakawa H., Ishibashi S., Tatsuhara S., 2010. Estimation of growth parameters within the Local Yield table Construction System for planted forests throughout Japan. Journal of Forest Planning, 15: 99-108.

Oka M., 2006. The study of analysis and valuation of harvesting operation by mechanization. $\mathrm{PhD}$ thesis of the University of Tokyo. (in Japanese. Title translated from Japanese)

Pukkala, T., 2002. Multi-objective forest planning. Boston: Kluwer Academic, 207 p. DOI: 10.1007/978-94015-9906-1

Reyer C. P. O., Bugmann H, Nabuurs G-J, Hanewinkel M., 2015. Models for adaptive forest management. Regional Environmental Change 15 (8):1483-1487. DOI: 10.1007/s10113-015-0861-7

Science Council, 2008. The policy to progress research development of global environmental science technology. Japanese Ministry of Education, Culture, Sports, Science and Technology, Tokyo, 40 p. (in Japanese)

Sinclair F. H., Stone G. N., Nicholls J. A., Cavers S., Gibbs M., Butterill P., Wagner S., Ducousso A., Gerber S., Petit R. J., Kremer A., Schoenrogge K. 2015. Impacts of local adaptation of forest trees on associations with herbivorous insects: implications for adaptive forest management. Evolutionary Applications 8 (10): 972-987. DOI: $10.1111 /$ eva.12329

Stankey G.H., Clark R.N., Bormann B.T., 2005. Adaptive management of natural resources: theory, concepts, and management institutions. US Department of Agriculture, Forest Service, Pacific Northwest Research Station, Portland, $73 \mathrm{p}$.

Vauhkonen, J., Packalen, P., Malinen, J., Pitkänen, J., and Maltamo, M. 2014, Airborne laser scanning based decision support for wood procurement planning. Scandinavian Journal of Forest Research 29(Suppl. 1): 132-143. DOI: $10.1080 / 02827581.2013 .813063$

Wang X., Zhong X., Gao P., 2010. A GIS-based decision support system for regional eco-security assessment and its application on the Tibetan Plateau. Journal of Environmental Management 91 (10): 1981-1990. DOI: 10.1016/j.jenvman.2010.05.006

West G. G., Turner J. A. 2014. MyLand: a web-based and meta-model decision support system framework for spatial and temporal evaluation of integrated land use. Scandinavian Journal of Forest Research, 29: 108-120. DOI: $10.1080 / 02827581.2013 .866690$

Wu J., Wang J., Li Y., Spong B. 2012. A web-based decision support system for analyzing timber harvesting costs and productivity. Northern Journal of Applied Forestry 29 (3): 141-149. DOI: 10.5849/njaf.11-007

Yousefpour, R., Hanewinkel, M. 2014. Balancing decisions for adaptive and multipurpose conversion of Norway spruce (Picea abies L. Karst) monocultures in the Black Forest area of Germany. Forest Science 60: 7384. DOI: 10.5849 /forsci.11-125 